\title{
Lung Nodules and Hypoxemia: Any Association?
}

\author{
Konstantina Chadia ${ }^{1}$, Paschalis Ntolios ${ }^{1}$, Stavros Anevlavis ${ }^{1}$, Paschalis Steiropoulos ${ }^{1}$ \\ 1. Pulmonology, University Hospital of Alexandroupolis, Alexandroupolis, GRC \\ Corresponding author: Paschalis Ntolios, pascnt@hotmail.com
}

\begin{abstract}
Pulmonary arteriovenous malformations (PAVMs) consist of aberrant circulation between pulmonary arteries and veins causing right-to-left shunt, uncommon and asymptomatic in the general population. We presented two patients, one presented with unexplained dyspnea and disease limited to the lung and the other with neurologic signs and systematic disease. Both patients were diagnosed with arteriovenous malformations and received embolization treatment successfully. Both patients received embolization treatment successfully.
\end{abstract}

Categories: Medical Education, Radiology, Pulmonology

Keywords: pulmonary arteriovenous malformation, interventional radiology guided embolization

\section{Introduction}

Pulmonary arteriovenous malformations (PAVMs), also known as pulmonary arteriovenous fistulae, pulmonary arteriovenous aneurysms, cavernous angiomas of the lung and pulmonary telangiectasias consist of aberrant circulation between pulmonary arteries and veins [1]. The normal anatomic barrier that should separate the pulmonary arterial from the venous circulation is lost, resulting in anatomic right-to-left shunt [2]. These lesions are uncommon in the general population with a prevalence of 1 in 2600 individuals and are 1.5-2 times more common among women than men [3-4], and usually become apparent after puberty, between the fourth and sixth decades. They can be picked up incidentally on chest imaging but also present as unexplained dyspnea or hypoxemia [2].

We hereby describe the diagnostic approach and treatment considerations in two patients. The first patient presented with unexplained dyspnea and disease limited to the lung, while the second patient with neurologic signs and systematic disease.

\section{Case Presentation}

\section{Case 1}

A 74-year-old, nonsmoker, female patient was referred to our outpatient clinic for low oxygen saturation and central cyanosis. She reported progressively worsening dyspnea (mMRC II/IV) during the last four years and nonproductive cough. Her medical history included dyslipidemia and arterial hypertension. No other

Review began 02/01/2021 Review ended 02/16/2021 Published 03/14/2021

\section{(c) Copyright 2021}

Chadia et al. This is an open access article distributed under the terms of the Creative Commons Attribution License CC-BY 4.0., which permits unrestricted use, distribution, and reproduction in any medium, provided the original author and source are credited. symptoms were reported.

On physical examination, her pulse rate was 65 beats $/ \mathrm{min}$ and respiratory rate 16 breaths $/ \mathrm{min}$. Blood pressure was $120 / 80 \mathrm{mmHg}$ and oxygen saturation on room air was $89 \%$. Lung and heart auscultation were normal. No murmurs or clubbing was observed. Rest of physical examination was unremarkable. Hemoglobin was $15.2 \mathrm{~g} / \mathrm{dL}$ and white blood cells and differential counts were normal. Serum urea was 27 $\mathrm{mg} / \mathrm{dL}$ and creatinine was $0.7 \mathrm{mg} / \mathrm{dL}$. Rest of laboratory tests were normal. Arterial blood gases (ABGs) sampling revealed type I respiratory failure (pO2 $55 \mathrm{mmHg}, \mathrm{pCO} 236 \mathrm{mmHg}, \mathrm{pH}: 7.45$, HCO3: $25 \mathrm{mmol} / \mathrm{L}$, FiO2: 21\%). Supplemental oxygen with a nasal cannula (4 L/min) provided only partial improvement of ABGs (pO2 59 mmHg, pCO2 38 mmHg, pH 7.43, HCO3: 25 mmol/L, FiO2: 33\%). A chest radiograph showed a right lung nodule without other pathologic signs.

Transthoracic bubble echocardiography confirmed the presence of right-to-left shunt, without visualization of any cardiac or large vessels defects. A post IV contrast chest CT (Figure 1) revealed a $9 \mathrm{~mm}$, well-defined nodule without calcification, confirming the presence of an arteriovenous malformation. Brain and abdominal CT were normal. 


\section{Cureus}

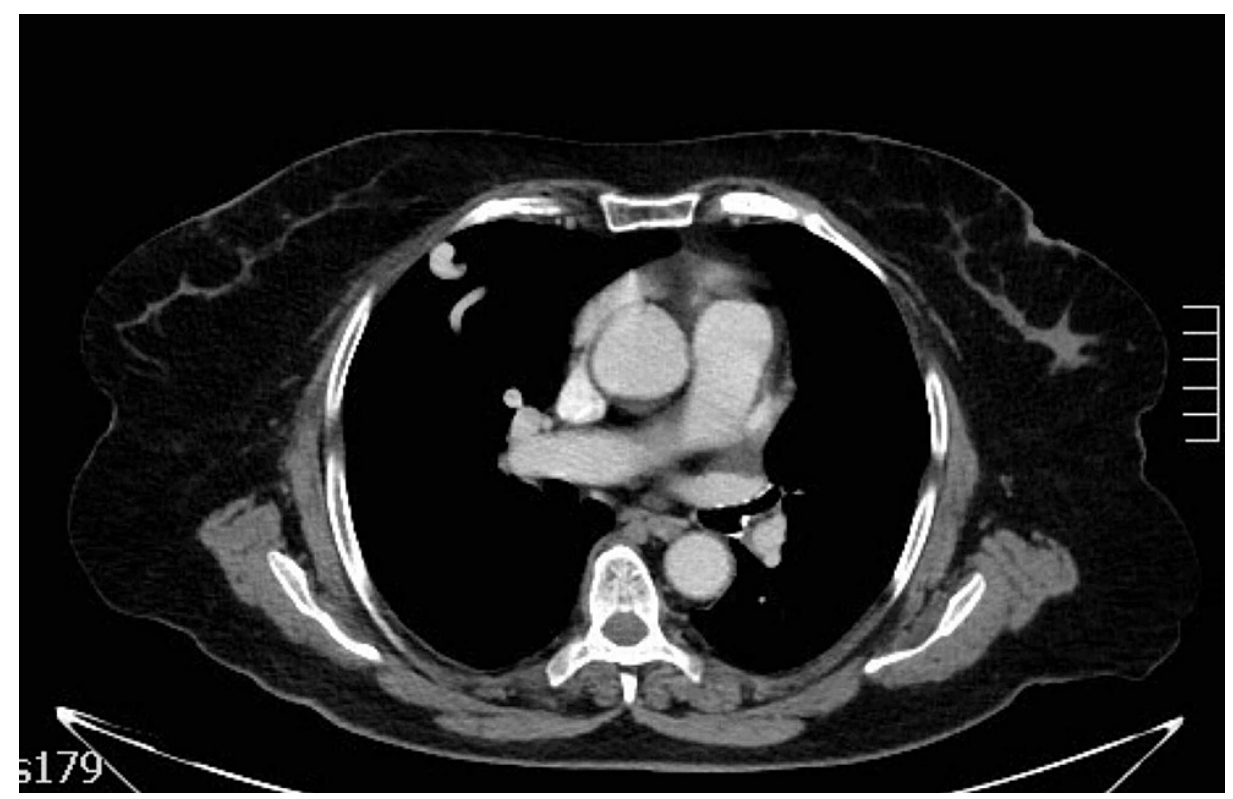

FIGURE 1: Contrast chest CT axial images shows a PAVM as a plexiform mass of dilated vascular channels.

PAVM, pulmonary arteriovenous malformation

Hereditary hemorrhagic telangiectasia (HHT) was excluded as a possible cause but no other cause could be identified. The patient underwent embolization by a chest radiologist with curative results.

\section{Case 2}

A 15 -year-old male patient was referred to the $\mathrm{ED}$, due to high fever $\left(39^{\circ} \mathrm{C}\right)$ lasting 72 hours, cervical stiffness and frontal headache. No other symptoms were reported.

On physical examination, pulse rate was 100 beats/min, respiratory rate was 12 breaths/min, and blood pressure was 120/80 $\mathrm{mmHg}$. Lung auscultation was normal. Cardiac sounds were normal with no murmurs. He did not have clubbing. His oxygen saturation was lower when supine (platypnea). Rest of physical examination was unremarkable. ABGs analysis revealed hypoxemia (pH: 7.45, pCO2: $36 \mathrm{mmHg}$, pO2: 68 mmHg, HCO3: 25 mmol/L, FiO2: 21\%). Routine laboratory investigations were normal. Hemoglobin was 11.1 $\mathrm{g} / \mathrm{dL}$. Liver and renal panels as well as inflammatory markers were within normal limits. The patient was suspected to have meningitis and was admitted to the Special Infections Unit. A brain CT revealed an enlargement of the left temporal horn. Lumbar puncture was performed and results from the cerebrospinal fluid analysis were 300 red blood cells/mm3, 5,800 nuclear cells/mm3, 30\% lymphocytes, and 70\% polymorphonuclear cells. Glucose was $41 \mathrm{mg} / \mathrm{dL}$, lactate dehydrogenase (LDH) $34 \mathrm{U} / \mathrm{L}$, and cerebrospinal fluid albumin $108 \mathrm{~g} / \mathrm{dL}$. Cerebrospinal fluid analysis revealed normal cell count and low protein levels. In addition, glucose was $101 \mathrm{mg} / \mathrm{dL}$ (serum concentration was $115 \mathrm{mg} / \mathrm{dL}$ ) and polymerase chain reaction (PCR), Gram stain and culture were negative for bacteria or bacterial and/or viral DNA and/or RNA. Chest radiograph was noticeable for three nodules in the right lung.

A subsequently post-IV contrast CT revealed numerous (>15) PAVMs in both lungs with the largest located in the right middle lobe and the superior segmental of the right lower lobe. They were perfused by branches of the pulmonary artery and had large draining veins (diameter $20 \mathrm{~mm}$ ) (Figure 2). 


\section{Cureus}

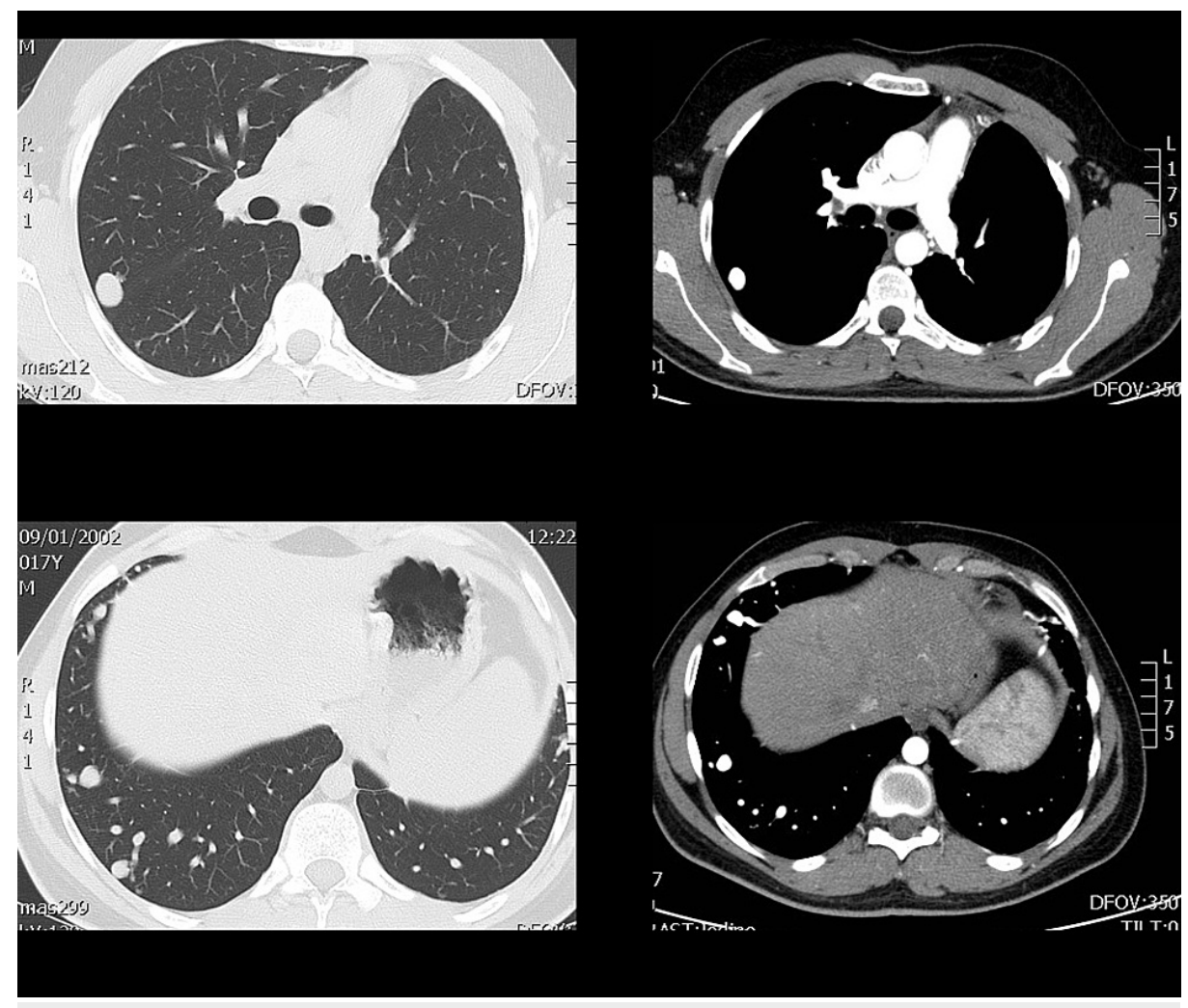

FIGURE 2: Axial CT images in the lung and soft tissue window show a large PAVM with a proximal tail-like extension and many smaller arteriovenous malformations.

PAVM, pulmonary arteriovenous malformation

A brain MRI was consistent with the diagnosis of a brain abscess with peripheral edema and hemorrhage in the right temporal lobe (Figure 3). 


\section{Cureus}

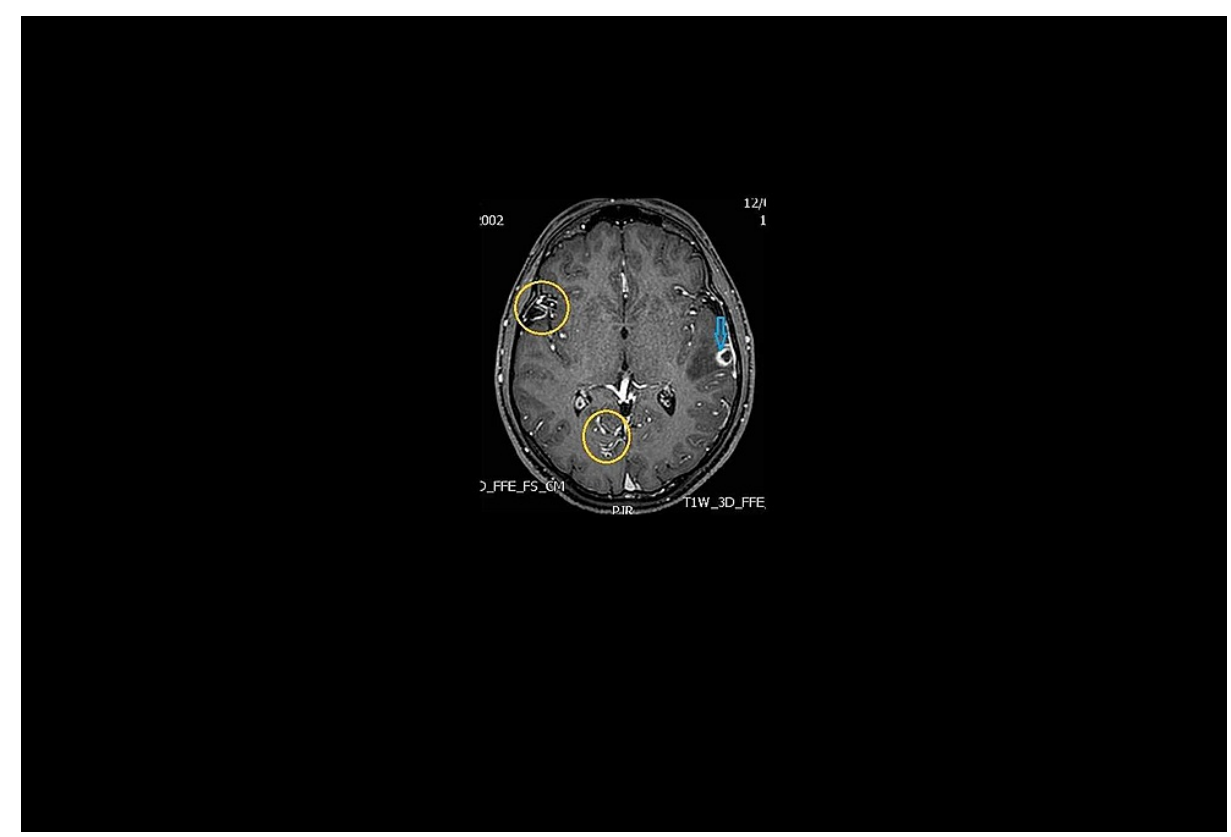

\section{FIGURE 3: Axial images of T1 weighted MRI of brain arterionenous malformations (yellow circles). The blue arrow shows the brain abscess's area.}

The largest one $(12 \mathrm{~mm})$ was located beside the interhemispheric fissure and was radiologically similar to those of a cavernous hemangioma. In addition, a more detailed history confirmed episodes of spontaneous nose bleeding and a first-degree relative with HHT (two out of three criteria for the diagnosis of HHT).

A contrast-enhanced pulmonary and abdominal aorta angiography was performed which confirmed the imaging findings of chest CT. Due to the presence of multiple arteriovenous malformations in multiple systems, this patient was referred to a specialized center for embolization.

\section{Discussion}

Heredity is an important factor in arteriovenous malformations. Most PAVMs are associated with HHT (also called Rendu-Osler-Weber syndrome), an autosomal dominant vascular disorder with an estimated prevalence of 25\%-98\% among patients with PAVMs [5]. Individuals with HHT usually develop symptoms progressively during their lifetime [4]. The diagnosis can be established through the use of the Curaçao diagnostic criteria that include spontaneous and recurrent epistaxis, multiple mucocutaneous telangiectasia at common sites (especially lips, fingers, oral cavity, and nose), visceral involvement (gastrointestinal, pulmonary, hepatic, cerebral, spinal) and a first-degree-relative with the disease. The diagnosis can be "definite" (3+ criteria), "suspected" (2 criteria), and "unlikely" (1 criterion) [6].

Even though most arteriovenous malformations are congenital, they can be caused by a variety of acquired medical conditions, hepatic cirrhosis being the most common one [7]. Less common associations include chest trauma, mitral stenosis, actinomycosis, and Fanconi's syndrome [8]. Surgical interventions for cyanotic congenital heart disease can also lead to PAVMs if the lung receives diminished hepatic venous return [9].

The PAVMs are classified as either simple (80\%-95\%) or as complex [10]. Simple PAVMs are perfused by a single feeding subsegmental artery and drained by a single vein, whereas complex PAVMs can have multiple perfusing and/or draining vessels [10]. In most situations, they are drained into the left atrium. They usually are multiple and vary in their number and distribution. Size is usually $1-5 \mathrm{~mm}$ but occasionally exceeding 10 $\mathrm{mm}$ [11]. The malformations usually manifest as a large single sac but can also appear as a lung mass consisting of dilated vessels [12].

Presentation can be asymptomatic and incidental, or with symptoms and even severe complications, some of which could be life threatening. This is usually determined by the right-to-left shunt size and the location of the malformations [9]. In some cases, brain abscess can be a complication of a bleeding brain arteriovenous malformation [13]. Spontaneous epistaxis caused by bleeding from mucosal telangiectases is the most common complaint in symptomatic patients (29\%-79\%), platypnea and orthodeoxia being the second $(13 \%-56 \%)$ [14]. Symptoms and possible complications include hemoptysis (7\%-30\%), telangiectasis 
(34\%-79\%), bruit (29\%-67\%), and cyanosis (0-54\%). Neurologic complications of PAVMs due to paradoxical embolization include migraines, ischemic strokes, and cerebral abscesses [2].

The diagnostic approach of PAVMs begins with the confirmation of a right-to-left shunt by transthoracic contrast echocardiography (TTCE), also known as "bubble echocardiography" [15]. TTCE has high sensitivity (100\%) and low specificity (49\%), a positive predictive value of $32 \%$, and a negative predictive value of $100 \%$ [15]. Confirmation of right-to-left shunt through TTCE should be followed by a chest CT scan [15]. Treatment used to depend on the size of the feeding artery. A diameter of more than 2-3 mm was considered an indication for pulmonary angiography and embolization [9]. This threshold is no longer considered valid and all visible PAVMs are candidates for embolization [14]. Asymptomatic patients should also be subjected to treatment, due to increased risk of paradoxical emboli and hemorrhage and additionally to improve the right-to-left shunt [16]. Surgical removal is limited to cases unsuitable for embolization [9]. Patients who do not receive treatment are followed up by chest CT every three to five years [9].

\section{Conclusions}

Pulmonary arteriovenous malformations should be part of the differential diagnosis of patients with unexplained dyspnea or hypoxemia. Initial presentation with brain abscess is rare but has been reported as a complication to a bleeding cavernous hemangioma. The presence of concomitant respiratory signs or symptoms should raise suspicion. Further diagnostic approach is important to confirm the presence of rightto-left shunt and provide an accurate visualization of PAVMs through chest CT scan. Embolization of the feeding artery remains the treatment of choice for all PAVMs regardless of size, due to the serious complications that include ischemic stroke and brain abscess in untreated patients.

\section{Additional Information \\ Disclosures}

Human subjects: Consent was obtained or waived by all participants in this study. Conflicts of interest: In compliance with the ICMJE uniform disclosure form, all authors declare the following: Payment/services info: All authors have declared that no financial support was received from any organization for the submitted work. Financial relationships: All authors have declared that they have no financial relationships at present or within the previous three years with any organizations that might have an interest in the submitted work. Other relationships: All authors have declared that there are no other relationships or activities that could appear to have influenced the submitted work.

\section{References}

1. Anabtawi IN, Ellison RG, Ellison LT: Pulmonary arteriovenous aneurysms and fistulas. Anatomical variations, embryology, and classification. Ann Thorac Surg. 1965, 1:277-285.

2. Cottin V, Dupuis-Girod S, Lesca G, Cordier J-F: Pulmonary vascular manifestations of hereditary hemorrhagic telangiectasia (Rendu-Osler disease). Respiration. 2007, 74:361-378.

3. Cottin V, Plauchu H, Bayle J-Y, Barthelet M, Revel D, Cordie J-F: Pulmonary arteriovenous malformations in patients with hereditary hemorrhagic telangiectasia. Am J Respir Crit Care Med. 2004, 169:994-1000.

4. Dines DE, Seward JB, Bernatz PE: Pulmonary arteriovenous fistulas . Mayo Clin Proc. 1983, 58:176-181.

5. Gossage JR, Kanj G: Pulmonary arteriovenous malformations. A state of the art review . Am J Respir Crit Care Med. 1998, 158:643-661.

6. Guttmacher AE, Marchuk DA, White RI Jr: Hereditary hemorrhagic telangiectasia. N Engl J Med. 1995, 333:918-924. 10.1056/nejm199510053331407

7. Krowka MJ: Hepatopulmonary syndrome and portopulmonary hypertension. Curr Treat Options Cardiovasc Med. 2002, 4:267-273. 10.1007/s11936-002-0007-3

8. Nakayama M, Nawa T, Chonan T, et al.: Prevalence of pulmonary arteriovenous malformations as estimated by low-dose thoracic CT screening. Intern Med. 2012, 51:1677-1681. 10.2169/internalmedicine.51.7305

9. Robin ED, Laman D, Horn BR, Theodore J: Platypnea related to orthodeoxia caused by true vascular lung shunts. N Engl J Med. 1976, 294:941-943. 10.1056/nejm197604222941711

10. Shovlin CL: Pulmonary arteriovenous malformations. Am J Respir Crit Care Med. 2014, 190:1217-1228. 10.1164/rccm.201407-1254CI

11. Shovlin CL, Guttmacher AE, Buscarini E, et al.: Diagnostic criteria for hereditary hemorrhagic telangiectasia (Rendu-Osler-Weber syndrome). Am J Med Genet. 2000, 91:66-67. 10.1002/(sici)10968628(20000306)91:1<66::aid-ajmg12>3.0.co;2-p

12. Shovlin CL, Jackson JE, Bamford KB, Jenkins IH, Benjamin AR, Ramadan H, Kulinskaya E: Primary determinants of ischaemic stroke/brain abscess risks are independent of severity of pulmonary arteriovenous malformations in hereditary haemorrhagic telangiectasia. Thorax. 2008, 63:259-266. 10.1136/thx.2007.087452

13. Borsaru AD, Naidoo P: Pyogenic abscess complicating a resolving cerebral haematoma secondary to a cavernous haemangioma: computed tomography and magnetic resonance imaging findings. Australas Radiol. 2005, 49:144-150.

14. Shovlin CL, Condliffe R, Donaldson JW, Kiely DG, Wort SJ; British Thoracic Society: British Thoracic Society Clinical Statement on Pulmonary Arteriovenous Malformations. Thorax. 2017, 72:1154-1163. 10.1136/thoraxjnl-2017-210764

15. Sloan RD, Cooley RN: Congenital pulmonary arteriovenous aneurysm. Am J Roentgenol Radium Ther Nucl Med. 1953, 70:183-210. 


\section{Cureus}

16. Wong HH, Chan RP, Klatt R, Faughnan ME: Idiopathic pulmonary arteriovenous malformations: clinical and imaging characteristics. Eur Respir J. 2011, 38:368-375. 10.1183/09031936.00075110 